\title{
Assessment of Soil Structural Properties in Relation to Land Use Change in South-East Asia ${ }^{+}$
}

\author{
Rachel de Lastic ${ }^{1}$, Thảo Hoàng ${ }^{2}$, Phuong Nguyen ${ }^{3}$, Sovanda Son ${ }^{4}$, Vuthy Suos ${ }^{4}$ \\ and Gunnar Kirchhof ${ }^{1, *}$ \\ 1 School of Agriculture and Food Sciences, University of Queensland, Brisbane, QLD 4072, Australia; \\ rachel.delastic@uqconnect.edu.au \\ 2 Northern Mountainous Agriculture and Forestry Science, Mai Son, Son La 360000, Vietnam; \\ hoangthao.nomafsi@gmail.com \\ 3 Faculty of Agronomy and Forestry, Tay Bac University, Son La City, Son La 360000, Vietnam; \\ hoangphuongtbu@gmail.com \\ 4 Conservation Agriculture Service Centre, Rattanak Mondul, Battambang 02200, Cambodia; \\ sovandason@yahoo.com (S.S.); suos.vuthyrua@yahoo.com (V.S.) \\ * Correspondence: g.kirchhof1@uq.edu.au \\ + Presented at the third International Tropical Agriculture Conference (TROPAG 2019), Brisbane, Australia, \\ 11-13 November 2019.
}

Published: 7 April 2020

\begin{abstract}
For many emerging economies, rapid land use change from forest to farmland is resulting in high levels of land degradation. Farming systems such as maize cultivation under conventional tillage after slash and burn degrade the soil resource through declining soil structural stability. Cultivation enhances mineralisation and hence loss of soil organic matter, which in turn reduces soil structures stability and promotes further carbon losses through soil erosion. Alternative land uses such as fruit tree plantations, or practise change to reduced tillage or conservation agriculture have the potential to counter this spiral of accelerated soil degradation through improving soil structural stability and build-up of soil organic matter. This project assessed how land use influences soil structural stability in Cambodia near Battambang and the North-Western Mountain regions of Vietnam where maize based system are most common. Soil properties measured were: (1) total carbon and nitrogen content analysis, (2) particle and aggregate size distribution using laser refraction, (3) hydraulic conductivity, (4) bulk density and (5) microbial $\mathrm{CO}_{2}$ respiration. Information on land use history was also collected through farmer surveys. Land use significantly influenced aggregate stability and hydraulic conductivity. This was largely associated with differences in soil organic carbon content. Forest system had the highest, and conventional maize systems had the lowest amount of large aggregates. Fruit tree plantations are relatively new to these regions but they already showed improved soil aggregate sizes though the level of improvement varied and depended on remnant soil.
\end{abstract}

Keywords: soil management; soil structure; land use

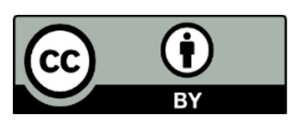

(C) 2020 by the authors. Licensee MDPI, Basel, Switzerland. This article is an open access article distributed under the terms and conditions of the Creative Commons Attribution (CC BY) license (http://creativecommons.org/licenses/by/4.0/). 